\title{
Influence of process variable on integrated power-temperature drying process for rambutan seed fat yield: a case study
}

\author{
${ }^{1}$ Ahmad, S., ${ }^{1 *}$ Anuar, M.S., ${ }^{1}$ Taip, F.S., ${ }^{1}$ Shamsudin, R. and ${ }^{2}$ Ab Mutalib, S.R. \\ ${ }^{1}$ Department of Process and Food Engineering, Faculty of Engineering, Universiti Putra Malaysia, 43400, \\ UPM Serdang, Selangor, Malaysia. \\ ${ }^{2}$ Food Technology Programme, School of Industrial Technology, Faculty of Applied Sciences, 40450, \\ Universiti Teknologi Mara Shah Alam, Selangor, Malaysia.
}

\section{Article history:}

Received: 28 May 2018

Received in revised form: 5 October 2018

Accepted: 5 October 2018

Available Online: 6

November 2018

\section{Keywords:}

Integrated power-

temperature,

Rambutan seed,

Fat yield,

Microwave finished oven,

Oven finished microwave

DOI:

https://doi.org/10.26656/fr.2017.3(2).115

\begin{abstract}
The effect of process variable namely; integrated sequence, variable intensity, drying time, and initial moisture content were studied on integrated power-temperature drying process for the rambutan seed fat yield. This study examined the effect of these parameters on fat yield and correlation between process variable on the integrated power-temperature drying process. Rambutan seeds that were dried at two different integrated sequences (microwave finished oven (MFO); oven finished microwave (OFM)) at three microwave power levels $(250,600$ and $1000 \mathrm{~W})$ with four different microwave time exposures $(5,10,20$ and 60 mins) and two oven temperatures $\left(45^{\circ} \mathrm{C}\right.$ and $\left.58^{\circ} \mathrm{C}\right)$ dried up to $1 \%$ of final moisture content for both level of initial moisture content (high and low). It was noted that fat yield was related with sequence, microwave power and microwave exposure significantly. Results were discussed in terms of sequence influence and relation between process variable on fat yield and how it is portrayed as an effective drying method for rambutan seed. These results will aid the integrated drying process development for agricultural products. The fat yield obtained through an efficient cost-effective drying process can help to promote the use of the rambutan fat yield in the industry, particularly the food industry.
\end{abstract}

\section{Introduction}

A short drying time leads to an effective drying process. Shorter drying time is often associated with having a lower energy consumption and therefore lower processing cost. Materials subjected to short drying time could retain its initial structure and nutrient content. Accordingly, the challenge to provide a shorter drying time to preserve product quality has become the main priority in drying process development. In order to reduce the drying time, countless interventions have been implemented including combining drying equipment which has different drying mechanisms to enhance the drying process in order to shorten the drying time. Examples of normal combined drying process such as involving both the convective and radiation drying on pumpkin (Ceclu et al., 2016), microwave and vacuum drying on edamame (Hu et al., 2006) and kiwifruit slice (Tian et al., 2015), convective and microwave drying on slice and pureed of strawberries (Venkatachalapathy and Raghavan, 2000), peeled longan (Varith et al., 2007), canola seed (Hemis et al., 2015), apple slice (Aghilinategh et al., 2015) and American ginseng (Ren and Chen, 1998), as well as hot air and vacuum drying on lettuce (Yuan et al., 2015).

The combination of these equipment is done through various ways, namely either concurrently or sequentially; referring to the implementation of both mechanisms into a single apparatus or for the case when each dryer is used sequentially. However, concurrent and sequential drying techniques were not properly differentiated in previous studies as they used the term combined or assisted alternately ambiguously. Previous research focused on the effect of combined drying mechanism on drying time, energy and cost consumption, as well as drying characteristics and behavioural of material. Significant improvements when using a combined drying mechanism was clearly presented via microwaveconvective drying as it provided a shorter drying time, better drying characteristics and behaviour as well as sustaining the dried quality product as shown in previous research on slice and pureed strawberries (Venkatachalapathy and Raghavan, 2000), peeled longan (Varith et al., 2007), canola seed (Hemis et al., 2015), apple slice (Aghilinategh et al., 2015) and American ginseng (Ren and Chen, 1998). 
Due to the ability to provide a competitive level in terms of drying time, cost and dried quality product, the microwave- convective drying was applied in this study. The drying combination applied in this study refers to the second type of drying combination, namely, sequential combination that involved sequence rotation in the dryer equipment. To avoid confusion on the type of combination drying mechanism used, the combined sequence applied is termed as "integrated" in this study. As combination sequence used in this study is microwave and forced convection oven, thus, the term drying combination utilized in this study is the integrated power-temperature drying process. Advantages of the combined drying mechanism has been observed on previous research, however, a higher technology is required in combining drying equipment to embed two different drying mechanisms as well as the need of practised labour and expensive production cost. As the material used in this study is rambutan seed which is agricultural waste and purpose of drying is for sustainable resources to produce a by-product for food (Lannes et al., 2003; Issara et al., 2014) and cosmetic (Lourith et al., 2016) industries as well as for medicinal purposes (Soeng et al., 2015). Thus, the low cost of drying process is required to ensure converted process of agricultural waste into by-product is effective and competitive in term of production cost and functional. Accordingly, integrated power-temperature drying process is applied in this study. Application of integrated power-temperature in this study should be able to reduce the drying time of rambutan seed that normally required 32 up to 48 hours under convective drying. A longer drying time exposure would most probably change the material structure, which in turn potentially degrade the dried quality product. However, in improving drying process through integrated power-temperature, there is some potential process variable that is believed to affect drying behaviour as well as the fat yield, which is the response in this study.

Therefore, the aim of this study is to examine the sequence influence on either microwave finished oven or oven finished microwave method that will provide an optimal drying condition as derived based on higher fat yield. The potential process variable, namely, are the integrated sequence (microwave finished oven (MFO) and oven finished microwave (OFM)), variable intensity (microwave power and the oven temperature), drying time (microwave exposure and oven exposure) and initial moisture content (high and low level). In addition, the pattern of relation between fat yield and these four process variables as well as the most significant process variable influence were also determined. As expected there is a significant effect of sequence applied on fat yield and all the process variables show a strong correlation and could affect the variability of fat yield with a higher percentage in multiple regression analysis. Thus, optimistically, these findings can give a new dimension to the industry upon the need for integrated drying variables in the drying process to increase the efficiency in terms of product quality. The scope and range studied are relatively lab-scale, thus; it is expected that the readers can assume the finding as a baseline data and subsequently need a proper scaling-up to industrial production level for adaptation purposes. The fat yield obtained through an efficient cost effect drying process can help to promote the use of the rambutan fat yield in the food industry.

\section{Materials and methods}

\subsection{Materials}

Rambutan was obtained from Taman Pertanian Universiti (TPU), Universiti Putra Malaysia. Fruit harvested were kept in zip-lock polyethylene bag at $8.5^{\circ}$ $\mathrm{C}$ in cool room prior deseeded. Fruit was deseeded manually, and the seed was washed and left at air room temperature $\left(24-25^{\circ} \mathrm{C}\right)$ to dry up surplus water at seed surface prior kept in double polyethylene zip-lock bag at $4^{\circ} \mathrm{C}$ in chiller model Protech SD-700 (Advanced Scientific, Malaysia). The initial moisture content of $5 \mathrm{~g}$ of seed was measured using a moisture analyzer (OHAUS MB45, UK) at $105^{\circ} \mathrm{C}$ for each batch prior to the drying process.

\subsection{Drying procedure}

Rambutan seed was dried by two cases of integrated drying variable based on different sequences; case 1; microwave finished oven (MFO) and case 2; oven finished microwave (OFM) respectively. In MFO, $20 \mathrm{~g}$ of rambutan seed with varied in initial moisture content (high; 30-45\% and low; 20-25\% $\mathrm{kg} \mathrm{H}_{2} \mathrm{O} / \mathrm{kg}$ dry basis) were dried by three different microwave powers 250 , 600 and $1000 \mathrm{~W}$ at 5,10,20 and 60 mins respectively and followed by automatic electric oven drying at two different temperatures of $45^{\circ} \mathrm{C}$ and $58^{\circ} \mathrm{C}$ until the final moisture content reached $1 \%$. The drying time required in automatic electric oven drying was based on the time needed to achieve $1 \%$ of final moisture content. After the drying time required in the automatic electric oven was known, then, case 2 (OFM) drying was performed. In OFM, $20 \mathrm{~g}$ of rambutan seed with varied in initial moisture content (high; 30-45\% and low; $20-25 \% \mathrm{~kg}$ $\mathrm{H}_{2} \mathrm{O} / \mathrm{kg}$ dry basis) were dried by automatic electric oven at two different temperatures; of $45^{\circ} \mathrm{C}$ and $58^{\circ} \mathrm{C}$ based on the previous drying time obtained in the second stage of case 1 (MFO) drying and finished by microwave at similar power levels and drying times. Weight loss was recorded every 5-min and 20-min intervals during 
microwave and automatic electric oven respectively. Weight loss was measured using an analytical balance AY220 model (Shimadzu, Japan) with precision up to $0.0001 \mathrm{~g}$. All samples were dried in duplicates in order to obtain an accurate, reliable, and robust experimental data. All experiment involved will be explained briefly by as Figure 1.

\subsection{Fat yield determination}

The extraction process of rambutan seed was carried out by soxhlet extraction method at $70-80^{\circ} \mathrm{C}$ for $8 \mathrm{hrs}$ upon constant particle size, $500 \mu \mathrm{m}$ of grounded rambutan seed dried with 1:10 ratio (dried powder: solvent). Hexane was used as an extractor agent prior to being evaporated by rotary evaporator at $40-55^{\circ} \mathrm{C}$. The organic residue obtained was then dried for $1 \mathrm{hr}$ at $103 \pm 2^{\circ} \mathrm{C}$ to calculate the fat yield. The fat yield from the rambutan seed was then measured using equation (1).

Fat yield $\%=\left(\frac{(a-b)}{c}\right) \times 100$

Where $a$ is the weight of round bottom flask after extraction; $b$ is the weight of round bottom flask before extraction; and $\mathrm{c}$ is the weight of sample before extraction.

\section{Results and discussion}

3.1 Effect of integrated sequence drying variable on fat yield

Both integrated sequences; MFO and OFM did not fall within a similar group even when it was tested within a similar drying variable range and was given a different set of fat yield means. This can be clearly explained by the significant $\mathrm{P}$ value of 0.001 ( $\mathrm{t}$-test) at alpha 0.05 . In addition, there is significant effect of different drying method (MFO: microwave finished drying; OFM: oven finished microwave) on fat yielding of dried rambutan seed by given a highly significant $P$ value $<0.0001$ at alpha 0.05 . Therefore, there is a need to perform the test for the mean separation to observe the different population means between drying method at alpha 0.05. According to tukey's mean separation, microwave finished oven (MFO) and oven finished microwave (OFM) sequences bringing their own capital letter B and A, respectively. This indicates there is a significant different between population means of sequences at alpha 0.05 and these sequences could significantly affected on fat yielding of dried rambutan seed. Besides, as OFM given a higher mean value compared to MFO, 37.897 and 32.316, respectively. Hence, OFM provide a better drying process of rambutan seed in terms of sequence in obtaining a higher fat yield compared to MFO. This may be due to effect of the combination of drying mechanism applied where it started with convective drying at higher level of moisture content and finished up by microwave drying at low moisture content which approaching to $1 \%$ of final moisture content that has been set up as cut point for drying process in this study.

A higher mean fat yield of rambutan seed obtained in OFM, 37.897, compared to previous studies that procured $34.34 \pm 0.77$ at $4.81 \%$ final moisture content by

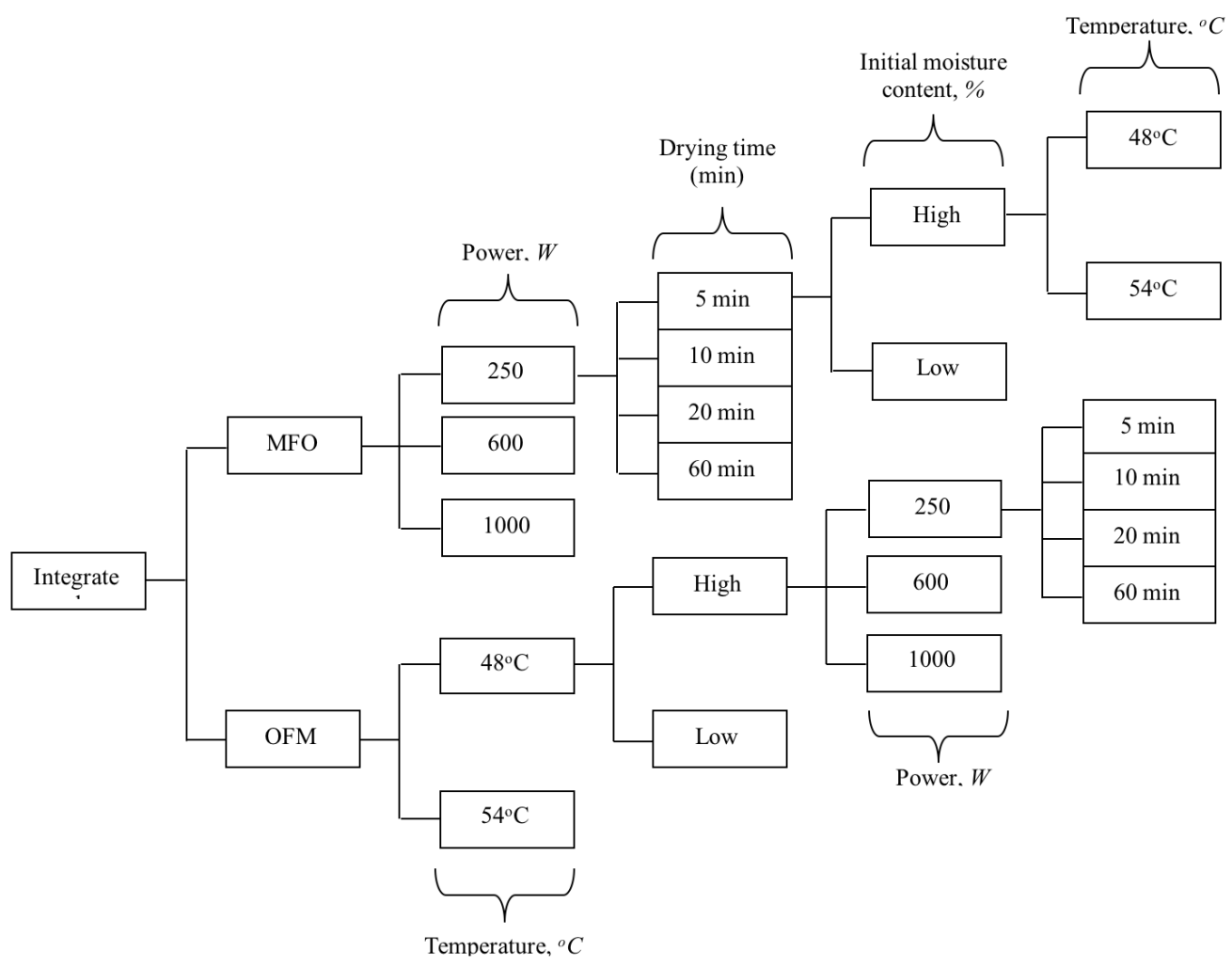

Figure 1. Experimental involved in integrated power-temperature drying process 
hot air dryer with 488 mins drying time or equivalent to more than $8 \mathrm{hrs}$ (Chimplee and Klinkesorn, 2015) was observed. A possible explanation for this due to integrated drying mechanisms of microwave and convective has overcome the drawback between each other and leading to a shorter drying time that is approximately less than two hours in total drying time and as well as increasing the extraction yield of rambutan seed fat. The higher fat yield obtained from the rambutan seed through the OFM sequence drying process could feasibly enhanced the functionality of rambutan seed fat in various industries such as mixing it with cocoa butter up to $30 \%$ in chocolate manufacturing in order to reduce cocoa butter usage (Manaf et al., 2013; Zzaman et al., 2014), providing a competitive defatted rambutan seed flour which is more nutritious than existing wheat flour (Eiamwat et al., 2015; Eiamwat et al., 2016), an ability to offer a modest fat source that had similar properties to vegetable oils which can potentially be used in personal care industry and cosmetics ingredient (Lourith et al., 2016), as well as an ability to be a renewal source of petrodiesel by having 160 biodiesel yield $\mathrm{kgha}^{-1}$ (Winayanuwattikun et al., 2008). Overall, this study highlights the need for enhancing the rambutan seed fat extracted with a shorter drying time that would provide a promising economical drying process through the lower energy consumption exhibited by the oven finished microwave sequence drying process. A similar finding also found for Thompson seedless grape as a better drying condition was obtained under a combined drying mechanism between microwave and convective dryers involved (Kassem et al., 2011).

\subsection{Relations of process variable involved on fat yield}

Correlation of each process variable on the fat yield of rambutan seed under integrated power- temperature drying process is shown in Table 1 . Two out of the five process variables involved insignificantly effects on the fat yield by giving insignificant $\mathrm{P}$ value at alpha 0.05 . Oven temperature (OT) is insignificantly affecting the fat yield under integrated drying process is probably due to the rambutan seed has reached the $1 \%$ of final moisture content, prior to entering the oven drying phase. Accordingly, when the subsequent drying process is using forced convection drying oven, it does not make any significant changes to the fat yield as observed in microwave finished oven (MFO) sequence. A similar trend can be observed for the oven finished microwave (OFM) sequence drying process was performed. This is because the drying time in oven is short due to the same drying exposure has been applied in the OFM to seek uniformity between MFO and OFM for comparison purposes. A short period of oven drying in the MFO is caused by the residual percentage of moisture content after microwave drying is near the $1 \%$ final moisture content as the cut point of the drying process in this study. Therefore, the rapid drying process reaching the $1 \%$ of final moisture content in the MFO is due mainly to the drying mechanism applied during the first phase involving microwave drying. Microwave drying mechanism involves collisions between moisture particles within the material that in turns generate heat internally and help facilitates the moisture removal from the rambutan seed. The seed normally consists of bound water and stored at deepest layer of material and need a longer drying time to release moisture particle under normal convective drying conditions. Thus, a longer drying time required if dried by forced convection during oven drying as water removal process occurs mainly due to the temperature gradient between the air and the surface material. The removal of water molecules happens until equilibrium exist in terms of the temperature between air and material. Thus, the convective drying mechanism required a longer drying time. Accordingly, a shorter drying exposure in the OFM unable to change the fat yield from the rambutan seed. This situation is clearly shown in the integrated drying process at higher microwave power level with longer microwave exposure up to 1 hour. Therefore, it is proposed to re-evaluate the range studied of microwave exposure and microwave power level in assessing the effect of integrated power-temperature drying process particularly for low moisture content material such as rambutan seed in this study.

Whereas, initial moisture content insignificantly affected the fat yield probably due to the level of moisture content is affecting the drying time. So, if the drying time has been set up, as in this study, thus, the initial moisture content could not significantly affect the fat yield.

Although the sequence, microwave power and microwave exposure significantly affected the fat yielding, it is represented in terms of a weak correlation as can be seen from the correlation for each process

Table 1. Correlation value of each process variable involved on fat yield in integrated power-temperature drying process

\begin{tabular}{cccccc}
\hline Indicator & Sequence (SQ) & $\begin{array}{c}\text { Oven Temperature } \\
(\mathrm{OT})\end{array}$ & $\begin{array}{c}\text { Microwave } \\
\text { Power (MP) }\end{array}$ & $\begin{array}{c}\text { Microwave } \\
\text { Exposure (ME) }\end{array}$ & $\begin{array}{c}\text { Initial Moisture } \\
\text { Content (IMC) }\end{array}$ \\
\hline$r$ & 0.24942 & 0.03334 & 0.28264 & 0.24240 & -0.09021 \\
P value & 0.0005 & 0.6462 & $<0.0001$ & 0.0007 & 0.2134 \\
\hline
\end{tabular}


variables involved $0.24942,0.28264$ and 0.24240 , respectively (Table 1). As these process variables significantly affected the fat yield, the most influence process variable upon fat yield could be predicted and in turn, the equation model consisting of process variable can be developed. This equation model is very important as baseline data for the subsequent work that focuses similar relationship but at a different range of process variables as well as for different materials which have similar structures.

Based on the assessment of multiple regression stepwise selection method, the microwave power becomes the most influential process variable on the fat yield from the rambutan seed compared with other process variables by giving a highly significant $\mathrm{P}$ value and the highest of $F$ value, 16.50 compared to 13.70 and 13.82 for sequence and microwave exposure respectively. The similar for $\mathrm{P}$ and $\mathrm{F}$ values were obtained for both probability levels and confidence intervals that have been studied which were at alpha 0.15 and 0.05 and confident interval of $85 \%$ and $95 \%$ respectively. These two levels of probabilities and confident intervals have been studied to evaluate if the range of the acceptance error has been increased; a higher value of $\mathrm{R}^{2}$ and lowest value of $\mathrm{C}_{\mathrm{p}}$ could be obtained. However, a similar regression value has been obtained, by given only $20.09 \%$ (Table 2 ) in fat yield variability could be explained by the linear regression as presented in equation (2);

$Y=19.81622+4.93660 S Q+0.00913 M P+0.11099 M E$

Table 2. Equation model at two alpha level and confident interval $\alpha=0.15$, confident interval $85 \%$ and $\alpha=0.05$, confident interval $95 \%$

\begin{tabular}{ccccc}
\hline \multicolumn{5}{c}{$\mathrm{Y}=19.81622+4.93660 \mathrm{SQ}+0.00913 \mathrm{MP}+0.11099 \mathrm{ME}$} \\
Step & $\mathrm{R}^{2}$ & $\mathrm{C}_{\mathrm{p}}$ & Variable & P value \\
\hline 1 & 0.0799 & 28.6631 & $+\mathrm{MP}$ & $<0.0001$ \\
2 & 0.1421 & 16.0145 & $+\mathrm{SQ}$ & 0.0003 \\
3 & 0.2009 & 4.1780 & $+\mathrm{ME}$ & 0.0003 \\
\hline
\end{tabular}

\section{Conclusion}

Based on the study conducted, oven finished microwave (OFM) exhibited a higher mean of fat yield, 37.897, compared to microwave finished oven (MFO), 32.316. Therefore, OFM can provide a promising alternative drying mechanism in terms of obtaining a higher fat extracted at a shorter drying time. In terms of the fat yield, an equation model presenting the relationship between fat yield and the process variable was developed and it showed that the microwave power as the most significant process variable. Therefore, it is expected that the model may provide a baseline data to researchers in improving the drying process via the integrated drying variables for agricultural products especially for the rambutan seed to obtain a higher fat yield for use in the industry, especially the food industry.

\section{Acknowledgement}

The authors gratefully acknowledge Universiti Putra Malaysia (UPM) for IPS research grant (vote no. 9464600) and Ministry of Higher Education as well as Applied Science Faculty, UiTM, Shah Alam for financial sponsored throughout this study.

\section{References}

Aghilinategh, N., Rafiee, S., Hosseinpour, S., Omid, M. and Mohtasebi, S.S. (2015). Optimization of intermittent microwave - convective drying using response surface methodology. Food Science and Nutrition, 3(4), 331-341. https://doi.org/10.1002/ fsn3.224

Ceclu, L.S., Botez, E., Nistor, O., Andronoiu, D.G. and Mocanu, G. (2016). Effect of different drying methods on moisture ratio and rehydration of pumpkin slices. Food Chemistry, 195, 104-109. https://doi.org/10.1016/j.foodchem.2015.03.125

Chimplee, S. and Klinkesorn, U. (2015). Thin-layer drying model of rambutan (Nephelium lappaceum L.) kernel and its application in fat extraction process. International Journal of Food Engineering, 11(2), 243-253. https://doi.org/10.1515/ijfe-20140209

Eiamwat, J., Wanlapa, S. and Kampruengdet, S. (2016). Physicochemical properties of defatted rambutan (Nephelium lappaceum) seed flour after alkaline treatment. Molecules, 21(364), 1-7. https:// doi.org/10.3390/molecules21040364

Eiamwat, J., Wanlapa, S., Sematong, T. and Reungpatthanapong, S. (2015). Rambutan (Nephelium lappaceum) seed flour prepared by fat extraction of rambutan seeds with $\mathrm{SC}-\mathrm{CO}_{2}$. Isan Journal of Pharmacentical Sciences, 10(Supp1.), 138-146.

Hemis, M., Choudhary, R., Gariepy, Y. and Raghavan, V.G.S. (2015). Experiments and modelling of the microwave assisted convective drying of canola seeds. Biosystems Engineering, 139, 121-127. https://doi.org/10.1016/j.biosystemseng.2015.08.010

Hu, Q.G., Zhang, M., Mujumdar, A.S., Xiao, G.N. and Sun, J. (2006). Drying of edamames by hot air and vacuum microwave combination. Journal of Food Engineering, 77(4), 977-982. https:// doi.org/10.1016/j.jfoodeng.2005.08.025 
Issara, U., Zzaman, W. and Yang, T.A. (2014). Rambutan seed fat as a potential source of cocoa butter substitute in confectionary product. International Food Research Journal, 21(1), 25-31.

Kassem, A.S., Shokr, A.Z., El-Mahdy, A.R., Aboukarima, A.M. and Hamed, E.Y. (2011). Comparison of drying characteristics of Thompson seedless grapes using combined microwave oven and hot air drying. Journal of the Saudi Society of Agricultural Sciences, 10(1), 33-40. https:// doi.org/10.1016/j.jssas.2010.05.001

Lannes, B.S.C.S., Medeiros, M.L. and Gioielli, L.A. (2003). Physical interactions between cupuassu and cocoa fats. Grasas Y Aceites, 54(3), 253-258. https:// doi.org/10.3989/gya.2003.v54.i3.239

Lourith, N., Kanlayavattanakul, M., Mongkonpaibool, K., Butsaratrakool, T. and Chinmuang, T. (2016). Rambutan seed as a new promising unconventional source of specialty fat for cosmetics. Industrial Crops and Products, 83, 149-154. https:// doi.org/10.1016/j.indcrop.2015.12.045

Manaf, Y.N.A., Marikkar, J.M.N., Long, K. and Ghazali, H.M. (2013). Physico-chemical characterisation of the fat from red-skin rambutan (Nephellium lappaceum L.) seed. Journal of Oleo Science, 62(6), 335-343. https://doi.org/10.5650/jos.62.335

Ren, G.X. and Chen, F. (1998). Drying of American ginseng (Panax quinquefolium) roots by microwave hot air combination. Journal of Food Engineering, 35(4), 433-443. https://doi.org/10.1016/S0260-8774 (98)00030-2

Soeng, S., Evacuasiany, E., Widowati, W. and Fauziah, N. (2015). Antioxidant and hypoglycemic activities of extract and fractions of rambutan seeds (Nephelium lappaceum L.). Biomedical Engineering, 1(1), 13-18.

Tian, Y., Wu, S., Zhao, Y., Zhang, Q., Huang, J. and Zheng, B. (2015). Drying characteristics and processing parameters for microwave-vacuum drying of kiwifruit (Actinidia deliciosa) slices. Journal of Food Processing and Preservation, 39(6), 2620-2629. https://doi.org/10.1111/jfpp.12512

Varith, J., Dijkanarukkul, P., Achariyaviriya, A. and Achariyaviriya, S. (2007). Combined microwave-hot air drying of peeled longan. Journal of Food Engineering, 81(2), 459-468. https:// doi.org/10.1016/j.jfoodeng.2006.11.023

Venkatachalapathy, K. and Raghavan, G.S.V. (2000). Microwave drying of whole, sliced and pureed strawberries. Agricultural Engineering Journal, 9(1), 29-39.

Winayanuwattikun, P., Kaewpiboon, C., Piriyakananon,
K., Tantong, S., Thakernkarnkit, W., Chulalaksananukul, W. and Yongvanich, T. (2008). Potential plant oil feedstock for lipase-catalyzed biodiesel production in Thailand. Biomass and Bioenergy, 32(12), 1279-1286. https:// doi.org/10.1016/j.biombioe.2008.03.006

Yuan, Y., Tan, L., Xu, Y., Yuan, Y. and Dong, J. (2015). Optimization of combined drying for lettuce using response surface methodology. Journal of Food Processing and Preservation, 40(5) , 1027-1037.

Zzaman, W., Issara, U., Febrianto, N. and Yang, T. (2014). Fatty acid composition, rheological properties and crystal formation of rambutan fat and cocoa butter. International Food Research Journal, 21(3), 1019-1023. 